\title{
Ovarian Angiosarcoma
}

National Cancer Institute

\section{Source}

National Cancer Institute. Ovarian Angiosarcoma. NCI Thesaurus. Code C5232.

A malignant vascular neoplasm arising from the ovary. 